\section{Arteriosclerosis or Vasculitis? Color Duplex Sonography in Giant Cell Arteritis}

\section{To the Editor:}

We followed with great interest the report by Czihal, et $a l^{1}$ presenting new possibilities of objective, noninvasive diagnostic procedures that remain insufficient in giant cell arteritis (GCA). We would like to share our clinical experiences with arteritic changes in patients with GCA.

Sonographic presentations of vasculitis may be mistaken for arteriosclerosis, especially in elderly patients who typically have GCA. That was the case in a patient with mild systemic manifestations and insidious disease onset. A 64-year-old woman presented with carotidynia - a rare manifestation of GCA. Color duplex sonography (CDS) revealed hypoechoic, homogenous, circumferential but not symmetrical bilateral wall thickening involving carotid and internal carotid arteries up to $15 \mathrm{~mm}$ from the carotid bifurcation (Figure 1). The diagnosis of GCA was confirmed by a superficial temporal artery biopsy. An initial diagnosis of arteriosclerosis with long, uncalcified plaques in a patient suspected to have GCA requires reexamination. In the absence of clinical context the differential diagnosis of vascular changes may still be difficult.

The problem of differentiating arteriosclerosis from vasculitis using CDS examination is their possible close relationship. Vasculitis and its treatment with glucocorticosteroids may promote accelerated arteriosclero$\operatorname{sis}^{2,3}$. Moreover, calcifications in temporal artery biopsies belong to the histological picture of GCA. Some studies speculate that arterial calcifications in elderly patients may promote giant-cell formation and vasculitis ${ }^{4}$. Czihal, et $a l^{1}$ describe "spot calcifications" or "beaded tube" appearance in lower extremity arteries of $65.5 \%$ patients classified as having vasculitis. It remains to be determined whether this represents a subtype of arteriosclerotic lesions, and if so is it primary or secondary to vasculitis? Whether this represents a specific sign of GCA also remains an important question for future studies. We may confirm this finding in some of our patients with GCA. For example, an 80-year-old woman was admitted to our department of rheumatology with pyrexia of unknown origin and cranial manifestations of GCA. She developed symptoms of intermittent claudication; however, she did not specifically describe them. They were mistaken with her chief complaints of general malaise and weakness and were attributed to polymyalgia rheumatica. Her CDS examination revealed an unusual appearance (Figure 2) similar to that reported by Czihal, et al. Afterwards, she was tested for pain-free walking distance; it appeared to be about 200 $\mathrm{m}$, but it doubled shortly after induction of glucocorticosteroid therapy. We also agree with Czihal, et al that the experience with patients with GCA is strongly influenced by the profile of the department. Most of our patients show cranial manifestations of the disease. It may therefore be difficult to estimate the prevalence of femoropopliteal involvement in GCA.

Whether wall thickening is related to vasculitis or arteriosclerosis might be supported by the improvement or lack of improvement after proper treatment in patients with GCA. This was demonstrated in studies on contrasted computerized tomography of the aorta ${ }^{5}$. The improvement of the aortic wall thickening was usually partial ${ }^{6}$. However, no improvement after the treatment was found by Czihal, et al or in other studies based on $\mathrm{CDS}^{7}$. Thus, more data from prospective studies are needed.

We agree with Czihal, et al that CDS imaging of the arteries should be recommended in patients with suspected GCA, and evaluated further in prospective studies.

MARCIN MILCHERT, MD, PhD; KATARZYNA FISCHER, MD, PhD; JACEK FLICINSKI, MD, PhD; HANNA PRZEPIERA-BEDZAK, MD, PhD MAREK BRZOSKO, MD, PhD, Professor, Department of Rheumatology and Internal Medicine, Pomeranian Medical University, ul. Unii Lubelskiej 1, 71-252 Szczecin, Poland. Address correspondence to Dr. Milchert; E-mail: marcmilc@hotmail.com

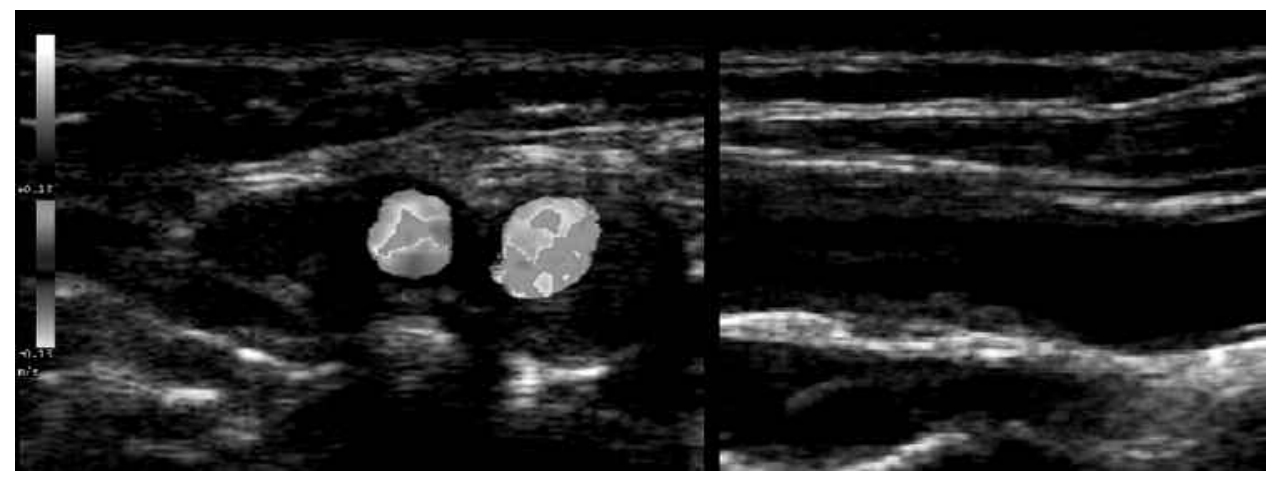

Figure 1. Color duplex sonography of left carotid arteries, transverse and longitudinal plane. Signs for vasculitis initially mistaken for those of arteriosclerosis

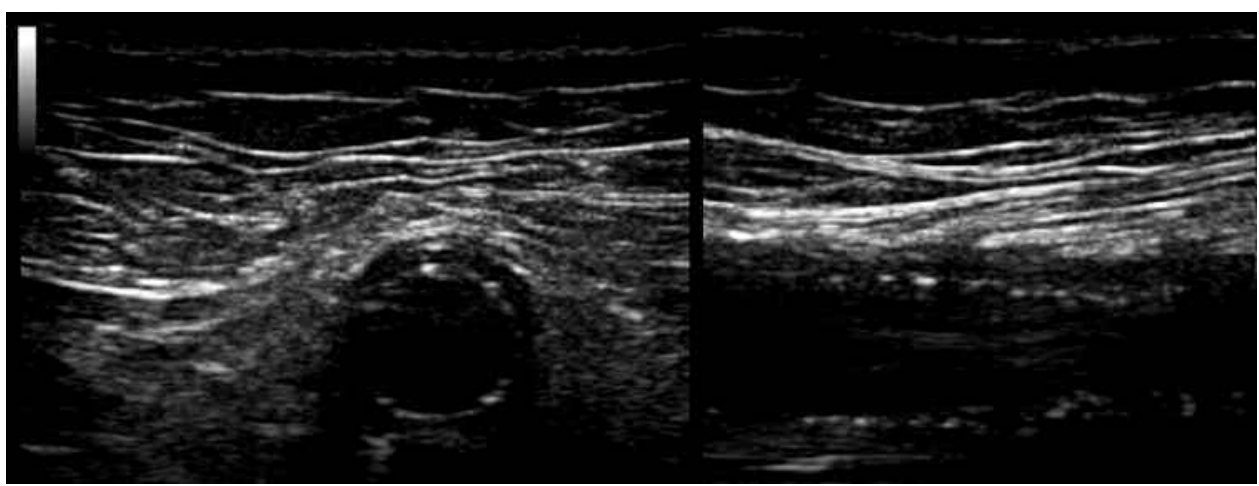

Figure 2. Color duplex sonography of left superficial femoral artery, transverse and longitudinal plane. Note "beaded tube" appearance, left panel. 


\section{REFERENCES}

1. Czihal M, Tatò F, Rademacher A, Kuhlencordt P, Schulze-Koops $\mathrm{H}$, Hoffmann U. Involvement of the femoropopliteal arteries in giant cell arteritis: Clinical and color duplex sonography. J Rheumatol 2012;39:314-21.

2. Fischer K, Brzosko M, Walecka A, Ostanek L, Sawicki M. Antiendothelial cell antibodies as a risk factor of atherosclerosis in systemic lupus erythematosus. Ann Acad Med Stetin 2006;52 Suppl 2:95-9.

3. Ohara N, Miyata T, Kurata A, Oshiro H, Sato O, Shigematsu H. Ten years' experience of aortic aneurysm associated with systemic lupus erythematosus. Eur J Vasc Endovasc Surg 2000;19:288-93.

4. Brouns K, Verbeken E, Degreef H, Bobbaers H, Blockmans D. Fatal calciphylaxis in two patients with giant cell arteritis. Clin Rheumatol 2007;26:836-40.
5. Milchert M, Brzosko M. Comment on "Polymyalgia rheumatica as the manifestation of unclassified aortitis". Mod Rheumatol 2008;18:427-8.

6. Marie I, Proux A, Duhaut P, Primard E, Lahaxe L, Girszyn N, et al. Long-term follow-up of aortic involvement in giant cell arteritis: A series of 48 patients. Medicine 2009;88:182-92.

7. Aschwanden M, Kesten F, Stern M, Thalhammer C, Walker UA, Tyndall A, et al. Vascular involvement in patients with giant cell arteritis determined by duplex sonography of $2 \times 11$ arterial regions. Ann Rheum Dis 2010;69:1356-9.

J Rheumatol 2012;39;9; doi:10.3899/jrheum.120317 